'Becado Medicina Interna. Hospital del Salvador. Facultad de Medicina Oriente. Universidad de Chile. Santiago, Chile. 2Sección de Hematología, Servicio de Medicina. Hospital del Salvador. Santiago, Chile.

Recibido el 10 de julio de 2016 aceptado el 7 de junio de 2017.

Sin apoyo financiero.

Correspondencia a:

Javier Quilodrán Peredo Av. Salvador 364, Providencia. Santiago, Chile. quiloper@hotmail.com

\section{Plasmocitoma extramedular. Una rara causa de masa mediastínica}

\author{
JAVIER A. QUILODRÁN ${ }^{1}$, CAMILA PEÑA ${ }^{2}$, XIMENA VALLADARES $^{2}$
}

\section{Extramedullary mediastinal plasmacytoma. Report of one case}

Solitary extramedullary plasmacytomas represent 3\% of plasma cell neoplasms. Their most common locations are the upper gastrointestinal and respiratory tract. We report a 70-year-old male presenting with progressive dyspnea and cough. A chest radiography showed widened mediastinum. Chest computed tomography showed a mediastinal mass. A bronchoscopy showed an extrinsic compression and complete occlusion of the primary bronchus. A self-expandable prosthesis was installed in left bronchus. A population of plasmacytoid cells was evidenced in the mass biopsy. Immunohistochemistry revealed CD20+ and CD138+. These tumor cells stained positively for lambda light chains, but negatively for kappa chains. Therefore an extramedullary plasmacytoma was diagnosed. A multiple myeloma was discarded with a normal blood count, serum calcium and creatinine levels. Serum protein electrophoresis had a monoclonal spike, serum IgG was $1963 \mathrm{mg} / \mathrm{dl}$. Bone marrow aspiration had 1\% of plasma cells. Bone $x$-rays were normal. Computed tomographies of the neck, thorax, abdomen and pelvis ruled out other plasmacytomas. Eight cycles of chemotherapy with thalidomide, melphalan and prednisone were indicated, obtaining complete remission of the tumor. The review of the literature shows that mediastinal extramedullary plasmacytomas are extremely rare. They generally appear in men aged between 50 and 60 years. The treatment of choice is radiotherapy, but given the location in the present case, chemotherapy was considered the best option. Recurrence is approximately 10 to $30 \%$ and $10 \%$ of patients progress to myeloma, thus requiring close monitoring.

(Rev Med Chile 2017; 145: 812-815)

Key words: Mediastinal neoplasms; Plasma cells; Plasmacytoma.
L os plasmocitomas extramedulares (PEM) son una neoplasia de células plasmáticas muy infrecuente, que consiste en una infiltración de células plasmáticas de origen monoclonal, sin compromiso de médula ósea ni otras características sistémicas de mieloma múltiple. Los PEM representan cerca del 3\% de todas las neoplasias de células plasmáticas ${ }^{1}$. Aproximadamente el $80-90 \%$ de los casos comprometen el tracto aéreo-digestivo superior ${ }^{2,3}$. Por lo general, son neoplasias altamente radiosensibles ${ }^{4}$. Presentan una probabilidad de progresión a mieloma múltiple entre 11 a $30 \%{ }^{1}$. Se presenta el caso de un paciente con un PEM mediastínico que obligó a un enfoque diagnóstico y terapéutico especial para el caso.

\section{Caso clínico}

Paciente sexo masculino, de 70 años de edad. Consulta por disnea y tos no productiva de dos meses de evolución. Estudio con radiografía de tórax evidenció ensanchamiento mediastínico. 
Se realizó tomografía computarizada (TC) de tórax que mostró masa mediastínica, y una fibrobroncoscopia (FBC) que mostró una compresión extrínseca y oclusión completa de los bronquios principales. Evolucionó con importante compromiso respiratorio, requiriendo una nueva $\mathrm{FBC}$ de urgencia y se instaló prótesis autoexpandible en bronquio izquierdo. Además, se realizó una mediastinoscopia para obtener muestra histológica de la masa. La biopsia describió presencia de una población plasmocitoide, cuya inmunohistoquímica reveló células CD138 + y presencia de cadena liviana lambda +, diagnosticándose plasmocitoma. Se realizó estudio para descartar mieloma múltiple: hemograma normal, VHS $88 \mathrm{~mm} / \mathrm{h}$, calcio 9,7 $\mathrm{mg} / \mathrm{dL}$, creatinina plasmática $0,95 \mathrm{mg} / \mathrm{dL}$, electroforesis de proteínas plasmáticas (EFP) con peak monoclonal, cuantificación de inmunoglobulinas IgA $73 \mathrm{mg} / \mathrm{dL}$, IgG $1.963 \mathrm{mg} / \mathrm{dL}$ (aumentado) e IgM $80 \mathrm{mg} / \mathrm{dL}$. El mielograma mostró 1\% de células plasmáticas. Se realizó biopsia de médula ósea bilateral, que no mostró infiltración por células plasmáticas. Radiografías óseas sin lesiones. Además, se realizó TC de cuello, tórax, abdomen y pelvis que no mostró otros plasmocitomas.

Dada la situación anatómica del plasmocitoma no se realizó radioterapia (por los riesgos de complicaciones a largo plazo), decidiéndose realizar quimioterapia con talidomida, melfalán y prednisona según lo discutido en Comité Hemato-Oncológico del hospital. Se administraron 8 ciclos. Posterior a estos se realizó estudio para evaluar respuesta. Hemograma y bioquímica nuevamente fueron normales. VHS $15 \mathrm{~mm} / \mathrm{h}$. EFP normal (buen marcador de seguimiento dado su alteración al diagnóstico). TC de control no evidenció masas (no realizó PET por no disponibilidad en centro en este momento). Se consideró en remisión completa y por buena respuesta se confirmó plan de no realizar radioterapia. Actualmente el paciente se encuentra en observación luego de 2 años. En controles posteriores con PET-TC no se
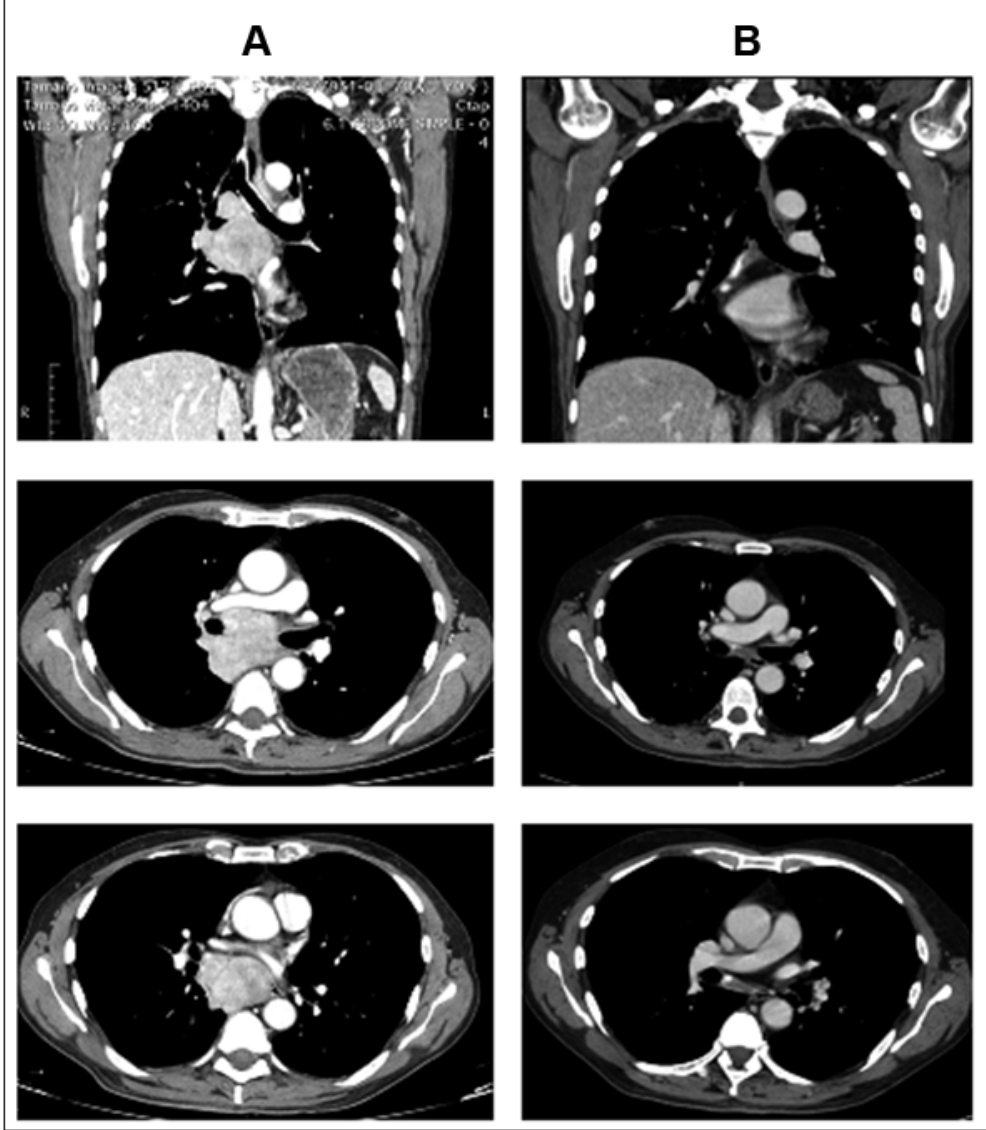

Figura 1. Imágenes de tomografía computarizada de tórax. A. Previo a quimioterapia; B. Posterior a quimioterapia. 
evidenció hipermetabolismo. El paciente entregó su consentimiento para la presente publicación.

\section{Discusión}

El plasmocitoma es parte de las llamadas neoplasias de células plasmáticas. En ausencia de compromiso de médula ósea la OMS reconoce dos tipos: el plasmocitoma óseo solitario y el plasmocitoma extramedular (PEM). Los PEM primarios son raros, constituyendo cerca del 3 al $5 \%$ de las neoplasias de células plasmáticas ${ }^{1}$. Se asocian a componente o proteína $\mathrm{M}$ en menos del 30\% de los casos y, de estar presente, desaparece al realizar tratamiento ${ }^{5}$, tal como sucedió en nuestro caso. La edad promedio de presentación es 55 años, siendo el $66 \%$ de los casos en mujeres ${ }^{1}$. La presentación en mediastino es muy rara ${ }^{2}$. Una revisión de la literatura en inglés entre 1928 a 2010 identifica sólo 12 casos de compromiso de mediastino ${ }^{3}$. Las presentaciones de los casos incluían masas mediastínicas aisladas o asociadas a derrame pleural ${ }^{6}$, o que impresionaban como nódulos pulmonares o hemangiomas, manifestaciones de miastenia gravis al diagnóstico ${ }^{7}$ o incluso como hallazgo ecocardiográfico ${ }^{8}$. El síntoma más característico de presentación fue la disnea ${ }^{3}$. Según la literatura, en $5 \%$ de los pacientes con diagnóstico de PEM se diagnostica mieloma múltiple en forma concomitante ${ }^{3,4}$, siendo este hallazgo cercano al 30\% cuando se presenta como masa mediastínica, obligando a la búsqueda de mieloma oculto en forma exhaustiva. Algunas publicaciones han sugerido la utilidad del uso de estudios con medicina nuclear en casos específicos con duda diagnóstica9. En nuestro caso se descartó razonablemente con mielograma y biopsia de médula ósea bilateral.

La forma de diferenciar el PEM de otros tipos de tumores o linfomas es por inmunohistoquímica, siendo positivo para CD138 y expresión de cadenas livianas citoplasmáticas monoclonales en las células plasmáticas malignas ${ }^{10}$.

El PEM es una neoplasia muy radiosensible, siendo la radioterapia externa la alternativa terapéutica para el control de la enfermedad en la mayoría de los casos, con dosis de 35 a 45 Gy en pacientes con tumores mayores de $5 \mathrm{~cm}^{1}$, con control local entre $80-100 \%$ y sobrevida libre de enfermedad a 10 años entre $50-65 \%{ }^{4,11}$. En caso de recurrencia o enfermedad diseminada la quimioterapia puede considerarse después de la radioterapia o la cirugía, así como en forma exclusiva en los casos asociados a mieloma múltiple ${ }^{12}$. Con radioterapia, asociada en algunos a casos a cirugía, se logran tasas de sobrevida global a los 10 años cercanas a 70\%. En nuestro caso como ya se mencionó, se decidió por quimioterapia por la difícil ubicación del tumor y el elevado riesgo de complicaciones mediastínicas a largo plazo. La progresión a mieloma múltiple se ha descrito entre 11 a $30 \%$ a los 2 años ${ }^{1}$. Algunos de los factores que se han reportado relacionados a progresión a mieloma son la edad (mayores de 63 años) y el tamaño tumoral (mayor a $5 \mathrm{~cm})^{1}$. Hasta la fecha, nuestro paciente sigue en remisión completa. $\mathrm{Si}$ bien no se pudo realizar inicialmente un PET-TC de control de terapia, posteriormente pudo realizarse y mostró ausencia de hipermetabolismo.

Creemos importante la comunicación de este caso dado su infrecuencia y la buena respuesta al manejo.

\section{Referencias}

1. Ahnach M, Marouan S, Rachid M, Madani A, Quessar A, Benchekroun S, et al. Extramedullary plasmocytoma relapsing at differents sites: an unusual presentation. Pan Afr Med J 2013; 14: 34.

2. Alexiou C, Kau RJ, Dietzfelbinger H, Kremer M, Spiess JC, Schratzenstaller B, et al. Extramedullary plasmacytoma: tumor occurrence and therapeutic concepts. Cancer 1999; 85 (11): 2305-14.

3. Shukla A, Bansal V, Bhutani R, Kumar G, Sharma J, Solanki S, et al. Extramedullary plasmacytoma presenting as a mediastinal mass. Turk J Hematol 2011; 28 (3): 228-31.

4. Tsang RW, Gospodarowicz MK, Pintilie M, Bezjak A, Wells W, Hodgson DC, et al. Solitary plasmacytoma treated with radiotherapy: impact of tumor size on outcome. Int J Radiat Oncol Biol Phys 2001; 50 (1): 113-20.

5. Hussain A, Singh M, Singh K, Bagga H. Multiple extramedullary plasmacytoma with lytic bony lesions: a rare case report. Case Rep Med 2013; 2013: 1-3.

6. Raci-Wetherbee E, Dincer HE. IgG myeloma presenting as a large mediastinal mass and pleural effusion. J Bronchology Interv Pulmonol 2012; 19 (1): 65-7.

7. Ahmed AR, Marchbank AJ, Nicholson AG, Wotherspoon AC, Ladas GP. Extramedullary plasmacytoma presenting with myasthenia gravis and mediastinal mass. Ann Thorac Surg 2000; 70 (4): 1390-2. 
8. Mallo R, Gottlieb K, Waggoner D, Wittenkeller J. Mediastinal plasmacytoma detected by echocardiography and biopsied with EUS-FNA. Ecocardiography 2008; 25 (9): 997-8.

9. Chim CS, Ooi GC, Loong F, Liang R. Unusual presentations of hematologic malignancies. Case 1. Solitary bone plasmacytoma: role of magnetic resonance imaging and positron emission tomography. J Clin Oncol 2004; 22 (7): 1328-30.

10. Luh SP, Lai YS, Tsai CH, Tsao TC. Extramedullary plasmacytoma (EMP): Report of a case manifested as a mediastinal mass and multiple pulmonary nodules and review of literature. World J Surg Oncol 2007; 27 (5): 123.

11. Liebross RH, Ha CS, Cox JD, Weber D, Delasalle K, Alexanian R. Clinical course of solitary extramedullary plasmacytoma. Radiother Oncol 1999; 52 (3): 245-9.

12. Masood A, Hudhud KH, Hegazi A, Syed G. Mediastinal plasmacytoma with multiple myeloma presenting as a diagnostic dilemma. Cases J 2008; 1 (1): 116. 